REVIEW ARTICLE

\title{
Evidence-based assessment in a transtheoretical and paradigmatic approach
}

\author{
Lidia Cierpiatkowska ${ }^{A, B, E, F}$, Emilia Soroko ${ }^{A, E, F, G}$, Dominika Górska ${ }^{A}$, Helena Sęk $k^{E}$ \\ Adam Mickiewicz University in Poznan, Poland
}

Evidence-based practice (EBP) is a defined proposal for how to integrate science and clinical practice that treats scientific evidence, particularly the results of empirical research, as a source of clinically useful and highly objective knowledge. We assume that the principles and standards of clinical practice defined in EBP have resulted in the emergence of many trans-theoretical models, but have also significantly influenced the credibility of practice derived from paradigmatic approaches.

The aim of the article is to share our reflections on two issues: 1) What clinical problems arise in non-standard situations in the application of evidence-based practice for the best clinical outcomes for a patient with mental health problems? 2) What methods of integrating patient data are used by clinical psychologists in a transtheoretical and paradigmatic approach in differential (assessment), structural-functional and epigenetic (case formulation) diagnosis? In connection with developed standards for diagnosis and the effectiveness of psychotherapy, we consider EBP particularly relevant for the theory and practice of clinical psychology.

\section{KEY WORDS}

transtheoretical and paradigmatic approach; assessment; case formulation; evidence-based assessment 


\section{BACKGROUND}

Clinical psychology is a field of theory, research and practice that is applicable in many areas of individual and social life. The development and the level of theoretical knowledge manifests itself in its consistency and versatility, in the quality of empirical research and its usefulness in practice (McAdams, 1994). At the same time, mutual relations between theory and clinical practice are constantly present in reflection on various aspects and new tasks of research and practice (Cierpiałkowska \& Sęk, 2015, 2016; Brzeziński, 2016). A particular challenge for "old" paradigmatic clinical psychology is the trans-theoretical trend (also called integrative, transparadigmatic), namely evidence-based practice (EBP), which is widely used in diagnostic and therapeutic decisions.

Evidence-based practice is a defined proposal for how to integrate science and clinical practice that treats scientific evidence, particularly the results of empirical research, as a source of clinically useful knowledge and at the same time highly objective and independent of a clinician's thinking. Evidence-based practice is the integration of knowledge about the best available research results with clinical expertise, in the context of the client's individual characteristics, preferences and culture (APA, 2006, p. 273). Although evidence-based practice initially appeared to be a completely new trend in psychology, it has also been suggested that mental health thinking is a way of thinking about mental health problems, and has inspired researchers to develop trans-theoretical models of mental disorders and behaviour, and recommended standards and rules for the conduct of clinical practice have led to important research examining assumptions in paradigmatic approaches, particularly cognitive-behavioural and psychodynamic approaches.

What is meant by evidence-based practice encompasses a very broad spectrum of psychology - from nomothetic to idiographic approaches (Spring, 2007). A nomothetic approach is used for the formulation of various generalised indications of normative character as to psychological, diagnostic and therapeutic behaviour in specific clinical cases, often issued by associations and professional organisations, as well as by various government agencies. Recommendations are based on systematic, often quantitative reviews of high-quality research. These recommendations address best practice for an average patient with a specific mental health problem, and examples of this are treatments that result from finding specific empirically supported treatments (ESTs).

The purpose of the article is to share our reflections on two issues: the first is rules for evidence-based practice, the best clinical decision-making for a patient with mental health problems; and the second is the way data integration is used by clinical psychologists in diagnostic procedures when referring to evidence-based knowledge in theoretical and paradigmatic approaches. Due to the standards developed by the American Psychological Association (APA) for the diagnosis of differential, structural-functional and epigenetic diagnosis and the standards that psychotherapy should perform, these issues are considered to be particularly important for clinical psychology. In this study, in terms of the application of mental health knowledge, we focus on the analysis of diagnostic and assessment problems rather than psychotherapy.

\section{EVIDENCE-BASED PRACTICE IN PSYCHOLOGY AND INTEGRATING SCIENCE WITH CLINICAL PRACTICE}

The classic model of evidence-based medicine (Sackett, 1996), which has been the basis for evidence-based practice in other areas related to health care, is idiographic, although it draws on knowledge gained mainly in a nomothetic way. Idiography is manifested in the fact that the best possible clinical decision for an individual case of a patient is based on three elements: 1) the best available evidence, 2) the values, preferences and circumstances associated with the patient, and 3) the practical proficiency of the clinician (expertise). In other words, the essence of evidence-based practice is the process of integrating these elements into the clinical, diagnostic and therapeutic decision-making process. The three elements are discussed in the literature from different sides and their significance is evolving.

Evidence is defined as research findings derived from systematic data collection by observation and experimentation, question formulation, and hypothesis testing (Satterfield et al., 2009). Sometimes, empirical evidence is placed in the centre, and sometimes its nature is discussed or it is indicated that it is a necessary but insufficient data source (see Spring, 2007). The weight of evidence is not absolute. Proposals for a hierarchy of evidence based on their scientific quality are created - a pyramid of evidence. The clinician seeking evidence should begin with the types of evidence considered as the best evidence (such as the summative reviews and meta-analysis), and in the absence of sufficient information available at this level, descend to the lower levels of the pyramid. Ongoing works on rewriting the meaning of proof in the process of its expansion are still underway, as is evident in the rebuilding of evidence hierarchies, including more and more types of research, such as qualitative research and case studies (Guyatt \& Rennie, 2007), and the resistance of the psychological environment prior to the unequivocal establishment of the hierarchy, as it shows the usefulness of 
different types of evidence for different purposes or practical questions (Satterfield et al., 2009). For example, longitudinal and cohort studies are considered to be the best sources of knowledge for forecasting, and randomised controlled trials are best for determining the efficacy of interventions. The value of the evidence is differently seen by the different parties involved in delivering and accepting help. For example, organisations will pay attention to financial risk and a clinician may value certain evidence as it develops skills and a sense of competence. Higher standards of practice can be expected when empirical evidence is adequately linked to practical needs (Walker, Collins, \& Mowery, 2014), both at the general level of combining the EBP with PBE (practice-based evidence - cf. Barkham, Hardy, \& Mellor-Clark, 2010) and at an individual level when a practitioner has easy access to the information that he/she needs (Fig. 1).

Patient values and preferences are another area highlighted in EBP. In evidence-based psychological practice, the area of patient preference has been clarified, including identity and socio-cultural factors (age, sex, ethnicity, social class, religion, income), functional status (e.g. ability to work), willingness to change, level of social support, treatment history and even development history (see Satterfield et al., 2009). Patient issues as an argument in making a clinical decision allow it to be adapted to the circumstances of a patient's life, resulting in, among other things, an increase in the chance of realisation of the results of the diagnosis and the resulting actions (see also interactive diagnosis, Kowalik \& Brzeziński, 2000). Although this source of knowledge is equivalent to others, it is quite difficult to actually apply it. Among many reasons, it is worth mentioning that the paternalist model is still present in health care (the provider makes the decision for the patient) and only the initial stage of the development of care takes into account cultural aspects (Spring, 2007). Patients need help clarifying their values and preferences in the context of the data provided, leading to the development of tools to measure these preferences. It is also important to be aware of the use of authority by psychological service providers, which makes EBP rather an impediment to placing the patient at the centre of actions (Sanders, Harrison, \& Checkland, 2008). It is therefore still a challenge as to where and when the patient's values and preferences and other contextual factors should enter the decision-making process (Satterfield et al., 2009).

The greatest controversy, however, is the practical expertise of the clinician. In Sackett's first model (1996), she was given the highest (highest placed circle) role. In the light of the results of the study, there is no difference between experts and novices in differential diagnosis (e.g. Ægisdóttir, White, Spengler, Maugherman, \& Anderson, 2006; Westen \& Weinberger, 2004), the omnipresence of cognitive errors (e.g. Garb, 2010), the predominance of statistical inference in clinical trials (Godoy, 2003), and the large role of non-specific factors in the effectiveness of psychological interactions. It seems that an important role may be played by the type of diagnosis and rarely empirically tested personal competencies of clinical psychologists, which is further complicated by the fact that personal difficulties occur in clinicians in contact with certain types of patients (see Cierpiałkowska \& Soroko, 2015). The question of how to integrate these information areas into decision-making has led to other proposals where clinical expertise is the ability to formulate practical questions and properly assess and integrate potentially heterogeneous data sources, for example if patient preferences are contradictory to the available best evidence. It would then have a central character and be above all other areas (patient, evidence). At the same time, there are completely different

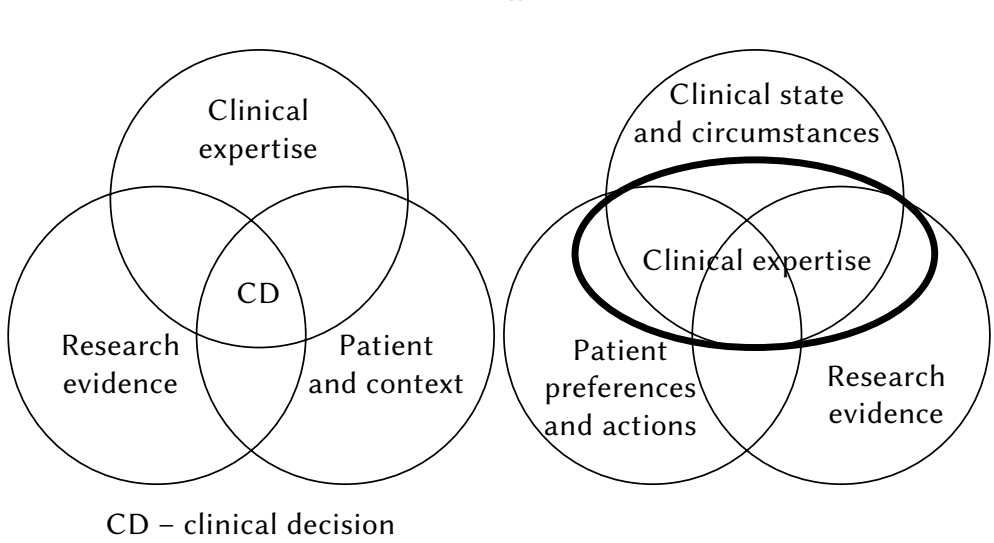

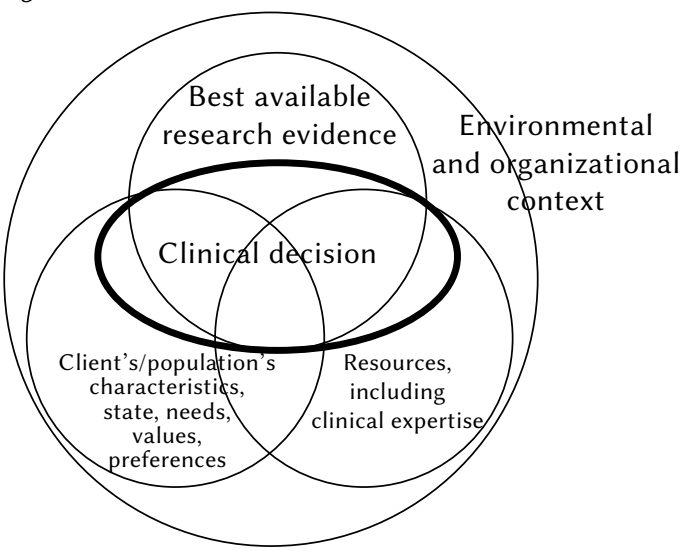

Figure 1. Evidence-based practice models: 1) Sackett's (1992) first three-circle model of evidence-based clinical decisions ; 2) Haynes's (2002) updated three-circle model; 3) Satterfield's (2009) revised EBP model. Based on: Satterfield et al. (2009). 
approaches where the decision-making process is placed in the centre as a cognitive activity that transforms evidence into contextualised evidence-based practice (Satterfield et al., 2009). Decision making is recognised here not as a specific individual skill, but a systematic decision-making process combining evidence with the customer, resources, and the context. This approach is applicable in treating EBP as a transdisciplinary approach (involving the cooperation of mental health professionals, patients and service providers, e.g. insurance companies, the Ministry of Health), aimed at improving responsibility for the effectiveness of health care and promoting lifelong learning (Spring, 2007). At the same time, an aspect not much taken into account is knowledge of the psychological decision-making processes in patient-clinician contact, in which more subtle interpersonal and intra-psychological processes occur. Evidence-based practice in the field of psychology has refined the notion of clinical proficiency by indicating the various constraints affecting the decision-making process, both those on the part of the clinician (e.g. cognitive errors, emotional processes) and those on the part of the patient (see Soroko \& Cierpiałkowska, 2016), as well as specific competencies (diagnosis, clinical judgement, case conceptualisation and formulation, treatment planning) and ways of gaining them (see also Tryon, 2010). The question how to identify, operationalise and train the required competencies - from transdisciplinary and individual perspectives - needed to complete specific practices remains important (Spring, 2007).

Clinical psychologists using EBP need procedures to take clinical decisions. To get beyond the most obvious reactions that are at the same time full of limitations, such as going back to education experiences, consulting peers, and quickly browsing the internet, clinical psychologists need methods to find answers to clinically relevant questions and keep up to date with academic literature (Walker \& London, 2007). The recommended approach to clinical decision-making in the literature is described in four main steps: ask for evidence, acquire evidence, appraise it, apply results, assess effects (5 x A, ask, acquire, appraise, apply, assess ${ }^{1}$, Walker, Collins, \& Mowery, 2014), with special attention being paid to asking relevant questions about evidence, since they determine both the selection of the best evidence and suggest where to look for it (Walker \& London, 2007; Walker, Collins, $\&$ Mowery, 2014). Questions are divided into background questions and foreground questions. Background questions fill gaps in knowledge and begin with "who", "what", "where", "how", “is" followed by the type of situation or disorder, such as "How is postnatal depression diagnosed and what treatment is most effective?", or "What risk factors for postnatal depression have been identified?" (this and the next example from: Walker, Collins, \& Mowery,
2007). Foreground questions concern a particular patient in a particular context, and it is recommended to formulate them according to the PICO format: patient group, intervention, comparison group, outcome measure. They may take the following form: "In a young woman with a history of depressive disorder, can evidence be found that cognitive-behavioural therapy administered before birth (I) will be more effective than no treatment $(\mathrm{C})$ in reducing the likelihood of developing postpartum depression $(\mathrm{O})$ ?" Although it is difficult to imagine that every foreground question will have a precise answer to the empirical knowledge already accumulated, the clear task of this question is an important step in the following stages of the procedure, that is to obtain evidence by deliberately searching databases with individual reports and - as is increasingly popular - with meta-analyses and systematic reviews of research, evaluate the information obtained, apply it in a patient-adapted manner and assess the effectiveness of the intervention.

\section{WAYS OF INTEGRATING DATA IN EVIDENCE-BASED ASSESSMENT - NON-PARADIGMATIC AND PARADIGMATIC APPROACHES}

An important development in the EBP trend is evidence-based assessment (EBA), which has been widely reflected in both non-paradigmatic and paradigmatic approaches. In the comprehensive definition of this trend, Hunsley and Mash (2007) emphasise that EBA is the use of the research and theory of normal and dysfunctional psychosocial functioning of a human being in order to select: 1) assessed constructs, 2) the way in which assessment procedures should be carried out, including the integration and interpretation of diagnostic data, and 3) good psychometric methods and tools. The selection of constructs, research tools, and ways of integrating data is related to the theoretical and clinical preferences of the clinical psychologist, who may be inclined either to more non-paradigmatic theories, referring to trans-theoretical approaches in psychology and related sciences, or to paradigmatic theories. Both approaches are justified in the light of empirical research conducted in line with EBP standards, and their purpose is to identify, based on reliable clinical diagnosis, the most effective treatment, usually involving pharmacotherapy and/or psychotherapy, in the context of the individual preferences of a person with mental disorders and behaviour.

Because there are three basic types of diagnosis in clinical psychology, i.e. differential, structural-functional-dynamic and epigenetic diagnosis (see Table 1; see Cierpiałkowska, 2007), it is to be assumed that not only is there a different way of gathering, inte- 
grating and interpreting diagnostic data, but each of these types is a source of different knowledge about normal and impaired intrapsychic functioning and its external manifestations, resulting in different ways of assessing the progress, development and effects of therapy. Differential diagnosis consists of diagnosing symptoms, meaning clinically important behaviour and experiences, then referring them to the description (matrix) of clinical conditions identified in medical classifications - ICD and DSM - and making decisions about health or mental disorders. Structural-functional diagnosis, also referred to as a case conceptualisation, aims to clarify the implications and/or significance of symptoms in the personality structure, while structural-dynamic diagnosis is used to clarify the significance of external factors (e.g. the behaviour of others, procedures or therapeutic intervention) or internal factors (e.g. different ways of thinking, fantasising about oneself) in activating or deactivating intrapsychic mechanisms leading to more or less adaptive behaviours of the patient. Constructs describing and clarifying functioning are understood specifically in non-paradigmatic and paradigmatic psychology. In the case conceptualisation, not only elements or aspects of personality are described, but above all the dynamic relationships between them, with particular attention to those mechanisms that sustain symptoms and/or adaptive behaviour. On the other hand, epigenetic diagnosis concentrates either on the role of biological and environmental factors in shaping the psychological structure underlying intrapsychic pathomechanisms and salutogenic mechanisms or on their direct influence on the manifestations of health and symptoms of mental disorders and behaviour (Cierpiałkowska \& Soroko, 2015). Here are some reflections on how to diagnose and integrate data obtained from the patient into specific types of diagnosis in an empirical evidence-based approach (also known as integrational) and a paradigmatic approach.

As already mentioned, differential diagnosis, also called specific, is primarily used to make quick and accurate clinical decisions based on the assessment of the severity and depth of psychiatric disorders, which usually have a different significance for further action in the paradigmatic and non-paradigmatic approach. In both approaches, the clinician during interviews or talks with the patient distinguishes significant clinical manifestations of mental and behavioural processes that correspond to the descriptions of mental disorders in classifications, and on the basis of similarity verifies hypotheses and formulates a particular clinical condition such as a mood disorder, anxiety disorder or their co-occurrence. While classification systems for mental disorders are criticised because they do not cover many of the mental disorders and problems of everyday life, their importance for early intervention is appreciat-
Table 1

Type of diagnosis, its effect and the process of assessment

\begin{tabular}{lc}
\hline Type of diagnosis & Effect \\
\hline $\begin{array}{l}\text { Differential } \\
\text { (nosological) }\end{array}$ & Nosological entity \\
Structural-functional- & $\begin{array}{c}\text { Psychological case } \\
\text { formulation: } \\
\text { dynamic }\end{array}$ \\
Epigenetic & a) pathomechanism \\
\hline
\end{tabular}

Assessment (process)

ed (Edwards \& McGorry, 2002). The paradigmatic approach emphasises that differential diagnosis based on ICD or DSM criteria is only part of the diagnostic process and may be an important therapeutic experience, but in no case does it end the gathering of patient information (e.g. Gabbard, 2009; Young, Klosko, \& Weishaar, 2013). In the non-paradigmatic approach, from the moment of making a differential diagnosis, greater attention is paid to the collection of data on the effects of therapeutic interventions, as this information is treated as an indicator of the accuracy of treatment (Dudley, Kuyken, \& Padesky, 2011). However, the decision on a particular type of treatment in both approaches is based on different premises and knowledge about the patient, which we try to show below.

Youngstrom and Van Meter (2016) proposed an assessment model (non-specific, non-paradigmatic) for making decisions on types of therapeutic interventions. Generally speaking, according to their procedure, the procedure begins with the establishment of a list of diagnostic hypotheses and referring them to the proportion of the underlying disorder or problem in the individual (the percentage of cases of a particular phenomenon forms the primary proportion of the problem in a clinic) and then proceeds to a determination of the risk factors by selecting screening scales or specific tests, and concludes with indicating a treatment (when the results of a disorder are high and the risk factors are low), supportive interventions (when the results of a disorder are high and the risk factors are low) or preventive measures (when the results of a disorder are low and the risk factors are high or low). Statistical probability is an important factor in a clinical decision, so the right selection of reference group is important. Comparison of the symptoms of psychiatric disorders and other characteristics of the person being tested with the characteristics of the reference group allow the accuracy of the diagnosis to be tested. By answering the question, "Do people in my study look like my patients, and if not, how much divergence can I tolerate?", it is 
possible to determine the probability of a credible diagnosis. Incorporating diagnostic information in this case means moving between the observed symptoms and the patient's mental state and the results of tests and the baseline data, while the behavioural model reflects the decision-making process (diagnosis and forecasting) based on external data in terms of the person making the diagnosis and the client.

In paradigmatic approaches, there is a more indirect link between recommended psychotherapy or health counselling and differential diagnosis, referring to a diagnosis only based on symptoms of mental and behavioural disorder, while there is more direct link with the results of structural-functional or structural-dynamic diagnosis. From the therapist's first contact with the patient, some therapeutic factors connected with the relationship may already be working, although making them specific and continuing them in the form of psychotherapy remains related to the case conceptualisation (e.g., Gabbard, 2009; Young, Klosko, \& Weishaar, 2013). A huge role in the case conceptualisation is played by combining symptoms (reported and observable) of a patient's normal and impaired functioning with theoretical constructs that allow for hypotheses, and then coherent explanations of the pathomechanism and mental health mechanism derived from a particular theoretical approach, using a specific paradigmatic language ("idiom dictionary"). Conceptualisation of a case requires the clinician to know and apply the assumptions and concepts of a particular paradigm. For example, a clinician using psychodynamic theory is required to: 1) know the theory of relations with the object, describing and explaining the development of the psychological structure and intrapsychic mechanisms underlying health and mental disorders; 2) refer to and discover (create hypotheses) of significant relationships between reported information (patient's life history) and observable information about the patient and in countertransference in the therapist to various aspects of the organisational and structural level of personality and co-occurring pre-oedipal and oedipal conflicts; 3) construct hypotheses about the dynamic relationships between external and internal factors and the activation of intrapsychic mechanisms from different levels of the organisation of personality, which are defined on the basis of relationships established and empirically confirmed within the theories; and 4) verify the reconstructed unconscious meanings and stories from the life of the patient during supervision (e.g. Perry, Cooper, \& Michels, 1987; Hinshelwood, 1991; Ingram, 2006; McWilliams, 2009). On the one hand, structural-functional-dynamic diagnosis is supported by the results of tests and personality questionnaires that derive from that approach, and on the other by verifying reported and observed patient responses to therapeutic interpretations.
The use of empirical knowledge and models in non-paradigmatic structural-functional diagnostics may be done in two ways - it may aim, on the one hand, to identify factors (phenomena, constructs) common to a wide range of psychiatric disorders, e.g. transdiagnostic factors (cf. Frank \& Davison, 2014), the identification and measurement of which is important for many mental disorders, and on the other hand to search for specific types and subtypes of disorders (constructs and behaviours). These two paths enable the integration of knowledge about the psychopathology (differences between the norm and the disorder) with the knowledge of individual conditions (cf. Cierpiałkowska, 2007).

Structural-functional diagnosis based on empirical evidence is an integrative approach in the sense that empirical models are used in the assessment, and the variables used in them are not directly related to knowledge from a particular psychological paradigm (which does not mean they cannot be inspired by them). These models are very different in character; for example, models that are useful in the diagnosis of personality are exchangeable with trans-theoretical models, hierarchical models of personality traits and personality disorders, and models of interpersonal relationships related to diagnostic relationships (Blais \& Hopwood, 2006; Hopwood, Zimmermann, Pincus, \& Krueger, 2015). Structural-functional diagnostic procedures also attempt to use models developed by representatives of disciplines other than psychology, for example cognitive science or neuroscience, in which complex cognitive and emotional-motivational constructs explain the determinants of more or less adaptive behaviours. Wide applications include, for example, Barnard and Teasdale's interacting cognitive subsystems model (1994) and the self-regulatory executive model function from Wells and Matthews (1996).

In the diagnosis of personality, for example, attention is paid to two transdiagnostic factors, internalisation and externalisation, behind which regulatory mechanisms in interpersonal relations are hidden (Blais \& Hopwood, 2006). Patterns of their occurrence in the population suggest that they have a biological origin (Eaton, Rodriguez-Seijas, Carragher, \& Krueger, 2015). Individual differences are organised into generalised groups of features that address personality disorders in general at the highest level, and externalising or internalising personality disorders, and specific features, such as those of the big five, at lower levels. This model in differential clinical diagnosis: 1) allows the coexistence of personality disorders to be explained, 2) allows decisions about the choice of the data generalisation level, ordering data according to the externalisation and internalisation cluster and their interpretation, and 3) is a basis for conceptualising features of personality disorders in dimensional categories, which allows characteristic profiles of the strengths of features. 
Knowledge of individual disorders not only enables the identification of key diagnosed variables but can also influence the shape of the tools used to measure them and how to diagnose them (see Hunsly \& Mash, 2007). For example, knowledge that anxiety disorders, if accompanied by any other psychiatric disorders, are more serious, leads to the recommendation that diagnosing co-occurring disorders must be an important element in the diagnosis of evidence-based anxiety disorders (EBA). On the other hand, empirically proven differences between self-reported anxiety and depression in young people and the assessment of symptoms by a parent lead to recommendations to seek data from different informants. In diagnosis of bipolar disorder in young people, due to documented difficulties in self-monitoring and reporting mood changes, repeated measurements over a longer period are recommended. The practice of using EBA is therefore influenced by how well the results of research into the utility of specific tools and methods of assessment are spread among clinicians and whether certain organisations are making recommendations or setting standards for assessment.

The ability to conceptualise a case for the psychotherapeutic process and the conceptualisation of treatment (in addition to salutomechanical or salutogenic explanations) is considered to be the most important cognitive clinical ability in both transparadigmatic and paradigmatic approaches (Eells, 2012; Eells, Kendjelic, \& Lucas, 1998; Freeman, Felgoise, \& Davis, 2008). It seems that such weight is attributed to conceptualisation because it requires the organisation and understanding of information provided in conversation, observation, diagnostic tools and self-monitoring of a clinician, but in the process of understanding data and creating a patient model in the mind of a psychologist. Achieving this goal of assessment requires the assumption of a relationship between the descriptive level (phenomena observable by quantitative and qualitative psychological tools) and the explanatory level (references to mental structures and processes in mentalist terms). In the psychodynamic or cognitive approach, the essence of the relationship between descriptive and explanatory variables is established and justified by theoretical assumptions, but in integrative models there is always a question of the nature of these relationships. For example, to create a coherent picture of psychological functioning that includes information about a high level of depression and hysteria in a person (descriptive level), interpretations are made in mentalist terms that a person uses hysterical defence against depression, which contributes to attention-attracting somatic symptoms (pathomechanism). Even in this thinking, we refer to a certain model of mental reality - the existence of psychological defences that can manifest in a certain way, but at the same time remain in relation to other difficulties, masking or distorting them. A question arises, which involves doubt as to the degree of use in case conceptualisation, in empirical integration models, of paradigmatic knowledge.

An important role for the quality and credibility of assessment, according to Hunsley and Mash (2007), is the quality of the assessment tools used by the clinician for data gathering. Practice based on empirical evidence - to bring useful information to clinicians must use research tools, methods and strategies that are of high scientific quality (especially psychometric) and which are published in good scientific journals, but at the same time they must be tools that are clinically significant and culturally sensitive (Therrien \& Hunsley, 2015). Some general recommendations can be made regarding tools used in diagnosis that are based on empirical evidence. Youngstrom and Van Meter (2016; Youngstrom, Choukas-Bradley, Calhoun, \& Jensen-Doss, 2014) recommend tests that have demonstrable diagnostic accuracy, are feasible in terms of utility and cost-to-profit ratio, and have a low correlation with previously used tests. At the same time, they add that to improve the quality of diagnosis it is important that clinicians do not ask themselves "Is this the best tool available?" but rather "Is this tool significantly better than what I have used so far?". Hunsley and Mash (2008), observing the relativity of psychometric values, promote the good enough criteria for the use of tools, which include: balancing psychometric ideals with clinical realism, incorporating in tools variables such as age, gender and ethnicity, and the fulfilment of criteria for normalisation, reliability and accuracy. Clinical relevance is also a criterion that they highlight - the extent to which the use of diagnostic data leads to a proven improvement in clinical services and leads to improved functioning of the client - which should be empirically investigated rather than presupposed, for example by disseminating tools among practitioners (e.g. studies show that conditions such as planning treatment where the use of the MMPI- 2 test does not affect the definition of improvement rates or premature end of treatment - see: Hunsley \& Mash, 2007).

Adopting EBA principles in both non-paradigmatic and paradigmatic approaches is associated with the recognition that even when using data from high-quality tools, the assessment process is a decision-making process in which the clinician must repeatedly formulate hypotheses by engaging in the integration of data that are often incomplete and inconsistent. Hence, in EBA a huge role is played by assessing the adequacy and usefulness of the decision-making task in light of potential errors in the synthesis and interpretation of data, as well as the costs associated with the assessment process and the awareness of the impact that the diagnostic process has on the person being diagnosed. 
The important role of the clinician's monitoring of their own involvement in the assessment process, which has a significant impact both on the outcome of treatment and on patients themselves, is being increasingly emphasised (see Hunsley \& Mash, 2007; Hayes \& Chen, 2008). Such monitoring of the assessment process involving a clinician is something that cannot be overestimated. It has at least two aspects: cognitive (awareness of the limitations of one's own mind, resulting from the nature of its functioning, cognitive economy, etc.) and personality - resulting from personal experiences, both unrelated and related to the assessment.

\section{SUMMARY}

Evidence-based practice encompasses a very broad spectrum of psychology - from nomothetic to idiographic approaches. It is not so much a new trend in clinical psychology, but rather, on the one hand, it is an attempt to apply certain principles and standards of conduct in paradigmatic approaches (e.g. psychodynamic and cognitive-behavioural approaches), and on the other hand, it has resulted in the creation of single process models as well as trans-theoretical psychological systems and mechanisms that are used in diagnostic and therapeutic procedures.

The analysis of ways of integrating patient data into the diagnostic process was considered in the context of differential, structural-functional, structural-dynamic, and epigenetic diagnosis in the psychotherapeutic process. We have shown considerable similarity in the evidence-based practice (transtheoretical) and paradigm-based approach to integrating directly observable, test and patient data into descriptive, differential diagnoses in which clinicians refer to the atypical ICD and DSM classifications of mental disorders and behaviours.

The biggest differences in data integration methods are evident in clarifying, structural-functional and epigenetic diagnoses. While in the evidence-based practice approach, the clinician formulates an epigenetic diagnosis primarily by referring to the best research into the patient's psychiatric problem, the clinician working in the psychodynamic or script theory approach focuses on structural-functional or dynamic-process diagnosis (the aim being to assess changes in the patient under the influence of psychotherapy), referring to the theoretical assumptions of intrapsychic mechanisms underlying the functioning of the individual. However, in terms of research effects in evidence-based practice and the trans-theoretical models of intra-psychic systems arising in it, the method of integrating data resembles that used in the paradigmatic approach. The diagnostician refers to the most useful and effective trans-theoretical model and explains the mechanisms of mental health persistence.
At present, there are also reports suggesting the use of certain trans-theoretical models developed within EBP in paradigmatic approaches, such as in diagnosis and therapeutic decisions in the cognitive-behavioural trend (Dudley, Kuyken, \& Padesky, 2011). Evidence-based practice has come full circle, starting with clinical practice and individual case studies, moving on to research among large groups of people with similar mental disorders, and ending up with formulating general trans-theoretical models and concepts of mental health.

\section{END NOTES}

1 Satterfield et al. (2009) give a different order: Assess, Ask, Acquire, Appraise, Apply. Clinicians assess the patient and clinical situation, ask relevant clinical or treatment questions, acquire evidence or other data, appraise the collected data, and apply the indicated treatment.

\section{REFERENCES}

APA Presidential Task Force on Evidence - Based Practice. (2006). Evidence-Based practice in psychology. American Psychologist, 61, 271-285.

Barkham, M., Hardy, G. E., \& Mellor-Clark, J. (eds.). (2010). Developing and delivering practice-based evidence: A guide for the psychological therapies. Chichester: Wiley.

Blais, M. A., \& Hopwood, Ch. J. (2016). Model-basedapproaches for teaching and practicingpersonalityassessment, Journal of Personality Assessment. doi: 10.1080/00223891.2016.1195393

Brzeziński, J. M. (2016). Towards a comprehensive model of scientific research and professional practice in psychology. Current Issues in Personality Psychology, 4, 1-10.

Cierpiałkowska, L. (2007). Psychopatologia [Psychopathology]. Warszawa: Wydawnictwo Naukowe Scholar.

Cierpiałkowska, L., \& Sęk, H. (2015). Wyzwania dla psychologii klinicznej XXI wieku [Challenges for clinical psychology in the XXI century]. Nauka, 2, 69-85.

Cierpiałkowska, L., \& Sęk, H. (2016). Naukowe i społeczne wyzwania dla psychologii klinicznej. [Scientific and social challenges for clinical psychology]. Roczniki Psychologiczne, 19, 406-436.

Cierpiałkowska, L., \& Soroko, E. (2015). Oblicza doświadczenia zawodowego w diagnozie klinicznej. Komentarz do Trzebińskiej i Filipiak [The faces of professional experience in clinical assessment. A Comment on Trzebińska and Filipiak]. Roczniki Psychologiczne, 18, 1, 97-108. 
Dudley, R., Kuyken, W., \& Padesky, Ch. (2011). Disorder specific and trans-diagnostic case conceptualization. Clinical Psychology Review, 31, 213-224.

Eaton, N. R, Rodriguez-Seijas, C., Carragher, N., \& Krueger, R. F. (2015). Transdiagnostic factors of psychopathology and substance use disorders: a review. Social Psychiatry and Psychiatric Epidemiology, 50, 171-182. doi: 10.1007/s00127-0141001-2

Edwards, J., \& McGorry, P. D. (2002). Implementing early intervention in psychosis. Aguide to establishing early psychosis services. London: Martin Dunitz.

Eells, T. D., Kendjelic, E. M., \& Lucas, C. P. (1998). What's in a case formulation? Development and use of a content coding manual. Journal of Psychotherapy Practice and Research, 7, 144-153.

Eells, T. D. (2012). In support of evidence-based case formulation in psychotherapy (from the perspective of a clinician). Pragmatic Case Studies in Psychotherapy, 9, 5, 457-467.

Frank, R. I., \& Davison, J. (2014). The transdiagnostic road map to case formulation and treatment planning. Practical guidance for clinical decision making. Oakland: New Harbinger Publications, Inc.

Freeman, A., Felgoise, S. H., \& Davis, D. D. (2008). Clinical psychology integrating science and practice. Hoboken, New Jersey: John Wiley \& Sons, Inc.

Gabbard, G. O. (2009). Psychiatria psychodynamiczna w praktyce klinicznej [Psychodynamic psychiatry in clinical practice]. Kraków: Wydawnictwo Uniwersytetu Jagiellońskiego.

Garb, H. N. (2010). The social psychology of clinical judgment. In J. E. Maddux \& J. P. Tangney (eds.), Social psychological foundations of clinical psychology (pp. 297-311). New York: Guilford Publications, Inc.

Godoy, A. (2003). Clinical judgement. In R. Fernandes Ballesteros (ed.), Encyclopedia of psychological assessment. London: Sage.

Guyatt, G. H., \& Rennie, D. (2007). Users' guides to the medical literature: A manual for evidence-based clinical practice. Chicago: American Medical Association.

Hayes, B. K., \& Chen, T. H. (2008). Clinical expertise and reasoning with uncertain categories. Psychonomic Bulletin Review, 15, 5, 1002-1007. doi: 10.3758/PBR.15.5.1002

Haynes, R. B., \& Guyatt, G. H. (2002). Clinical expertise in the era of evidence-based medicine and patient choice. EBM notebook, 7, 22. Retrieved from http://ebm.bmj.com/. Accessed 3 May 2017.

Hinshelwood, R. D. (1991). Psychodynamic formulation in assessment for psychotherapy. British Journal of Psychotherapy, 8, 166-175.

Hopwood, C. J., Zimmermann J., Pincus, A. L, \& Krueger, R. F. (2015). Connecting personality structure and dynamics: Towards a more evidence-based and clinically useful diagnostic scheme. Journal of Personality Disorders, 29, 431-448. doi: 10.1521/ pedi.2015.29.4.431

Hunsley, J., \& Mash, E. J. (2007). Evidence-based assessment. Annual Review of Clinical Psychology, 3, $29-51$.

Hunsley, J., \& Mash, E. J. (2008). Developing criteria for evidence-based assessment: An introduction to assessments that work. In J. Hunsley \& E. J. Mash (eds.), A guide to assessment that work (pp. 3-35). New York Oxford.

Ingram, B. L. (2006). Clinical case formulations matching the integrative treatment. Plan to the client. Canada: John Wiley \& Sons, Inc.

Kowalik, S., \& Brzeziński, J., (2000). Diagnoza kliniczna [Clinical diagnosis]. In H. Sęk (ed.), Spoteczna psychologia kliniczna [Social clinical psychology] (pp. 213-236). Warszawa: Wydawnictwo Naukowe PWN.

McAdams, D. P. (1994). The person: An Introduction to personality psychology. Forth Worth: Hartcourt Brace Colledge Publishers.

McWilliams, N. (2009). Diagnoza psychoanalityczna [Psychoanalytical diagnosis. Understanding personality structure in clinical process]. Gdańsk: Gdańskie Wydawnictwo Psychologiczne.

Perry, P., Cooper, A. M., \& Michels, R. (1987). The Psychodynamic Formulation: Its Purpose, Structure, and Clinical Application. American Journal of Psychiatry, 144, 543-550.

Sackett, D. L., Rosenberg, W. M. C., Gray, J. A. M., Haynes, R. B., \& Richardson, W. S. (1996). Evidence-based medicine: What it is and what it isn't. British Medical Journal, 312, 71-72. doi: https://doi. org/10.1136/bmj.312.7023.71

Sanders, T., Harrison, S., \& Checkland, K. (2008). Evidence-based medicine and patient choice: the case of heart failure care. Journal of Health Services Research \& Policy, 13, 103-108.

Satterfield, J. M., Spring, B., Brownson, R. C., Mullen, E. J., Newhouse, R. P., Walker, B. B., \& Whitlock, E. (2009). Toward a transdisciplinary model of evidence-based practice. Milbank Quarterly, 87, 368-390.

Soroko, E., \& Cierpiałkowska, L. (2016). Jakość diagnozy klinicznej i jej uwarunkowania [Quality and determinants of clinical assessment]. In L. Cierpiałkowska \& H. Sęk (eds.), Psychologia kliniczna. Podręcznik akademicki [Handbook of clinical psychology] (pp. 263-280). Warszawa: Wydawnictwo naukowe PWN.

Spring, B. (2007). Evidence-based practice in clinical psychology: What it is, why it matters, what you need to know. Journal of Clinical Psychology, 63, 611-631.

Therrien, Z., \& Hunsley, J. (2015). Evidence-based assessment. In R. L. Cautin \& S. O. Lilienfeld (eds.), Encyclopedia of clinical psychology (pp. 1-3), John 
Wiley \& Sons, Inc. doi: 10.1002/9781118625392. wbecp 013

Tryon, W. W. (2010). Competencies in adult clinical psychology. In J. C. Thomas \& M. Hersen (eds.), Handbook of clinical psychology competencies (pp. 1-42). Springer Science \& Business Media.

Walker, B. B., Collins, C., \& Mowery, H. C. (2014). Evidence-based practice: Concepts and techniques for translating research into practice. In C. M. Hunter, C. L. Hunter, \& R. Kessler (eds.), Handbook of clinical psychology in medical settings. Evidence-based assessment and intervention (pp. 125-147). New York: Springer.

Walker, B. B., \& London, S. (2007). Novel Tools and Resources for Evidence-Based Practice in Psychology. Journal of Clinical psychology, 63, 633-642.

Wells, A., \& Matthews, G. (1996). Modelling cognition in emotional disorder: The S-REF model. Behaviour Research and Therapy, 34, 881-888.

Westen, D., \& Weinberger, J. (2004). When clinical description becomes statistical prediction. American Psychologist, 59, 595-613.

Young, J. E., Klosko, J. S., \& Weishaar, M. E. (2013). Terapia schematów. Przewodnik praktyka [Schema therapy. A practicioner's guide]. Sopot: Gdańskie Wydawnictwo Naukowe.

Youngstrom, E. A., \& Van Meter, A. (2016). Empirically supported assessment of children and adolescents. Clinical Psychology: Science And Practice, 23, 327-347. doi: 10.1111/cpsp. 12172

Youngstrom, E. A., Choukas-Bradley, S., Calhoun, C. D., \& Jensen-Doss, A. (2014). Clinical guide to the evidence-based assessment approach to diagnosis and treatment. Cognitive and Behavioral Practice, 22, 20-35.

Ægisdóttir, S., White, M. J., Spengler, P. M., Maugherman, A.S., \& Anderson, L. A. (2006). The meta-analysis of clinical judgment project: Fifty-six years of accumulated research on clinical versus statistical prediction. The Counselling Psychologist, 34, 341-382. 